
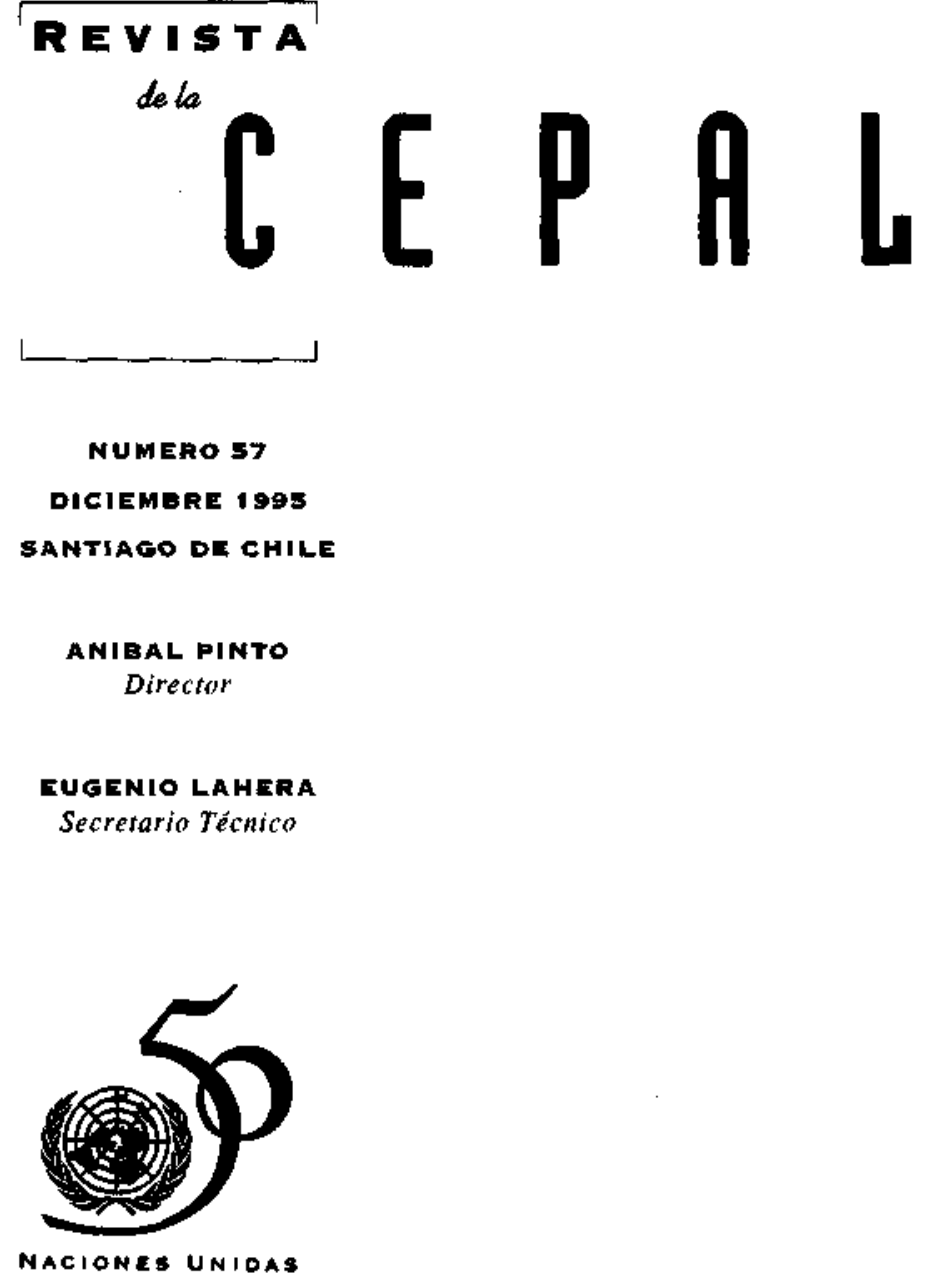
Las Naciones Unidas y la CEPAL en el

Cincuentenario de la Organización

Gert Rosenthal

La creación de las Naciones Unidas y de la CEPAL

Hernán Santa Cruz

Derechos humanos: el caso de los niños

Teresa Albánez

Gobernabilidad, competitividad e integración social

Fernando Calderón

Reforma laboral y equidad social:

la privatización de los puertos

Larry A. Burkhalter

Nuevas tendencias en las políticas salariales

Andrés E. Marinakis

Centroamérica: desempefio macroeconómico y

financiamiento social

Francisco Esquivel

Panamá y la integración económica centroamericana

Luis René Caceres

La dualidad del tipo de cambio en la economía cubana de los noventa

Archibald R.M. Ritter

Transnacionalización e integración productiva en

América Latina

Armando Di Filippo

Indice de autores y de temas en la Revista de la CEPAL, números 1 al 57

Orientaciones para los colaboradores de la Revista de la CEPAL 195 


\section{Panamá y la integración económica centroamericana}

\section{Luis René Cáceres}

Economista Principal,

Departamento de Planificación Estratégica, Banco

Interamericano de Desarrollo, Washington D.C.
En este artículo se examinan los beneficios que podría encontrar Panamá en una eventual integración con los países del Mercado Común Centroamericano (MCCA). Primero, se examina la estructura productiva de Panamá en términos del fenómeno conocido como el síndrome holandés; esto permite apreciar el efecto desindustrializante que los auges en el sector servicios han tenido sobre la economía. Luego se analizan las ventajas que Panama podría obtener de una gradual integración con los paises del MCCA en lo que hace a exportaciones intraindustriales, fomento de las inversiones, competencia y modernización productiva, y se postula que estos beneficios no estarían presentes, con carácter de reciprocidad, en un esquema de apertura unilateral. Se analiza también de qué manera la integración subregional podría impulsar una modernización productiva que contrarrestara los efectos adversos del síndrome holandés. Y por último, se presentan ecuaciones econométricas basadas en un modelo de gravedad y se cuantifica la mejoría apreciable que Panamá obtendría en su balance comercial con el MCCA si adhiriera plenamente a este esquema de integración. 


\section{Introducción}

En octubre de 1973 los países del Istmo Centroamericano - Costa Rica, El Salvador, Guatemala, Honduras, Nicaragua y Panamá- firmaron el Protocolo al Tratado General de Integración Económica Centroamericana, con el cual se actualizó el proceso de integración de manera coherente con las nuevas orientaciones de las políticas económicas nacionales e internacionales. Este Protocolo fue suscrito para ampliar el campo de acción sectorial e institucional de la integración y reflejar la voluntad política de los gobiernos centroamericanos de fortalecerla. La firma por Panamá de dicho Protocolo se podría interpretar como un paso hacia su adhesión al programa de integración centroamericana. Desde hace varias décadas, Panamá y el Mercado Común Centroamericano (MCCA) -integrado por los otros cinco países del Istmo-- han cultivado su acercamiento. Ejemplos de ello son la participación de Panamá en organismos como el Instituto Centroamericano de Administración Pública y el Instituto de Nutrición para Centroamérica y Panamá; su adhesión al Parlamento Centroamericano en agosto de 1994; su asistencia a los foros presidenciales y ministeriales de la subregión a partir de 1990 , y el aumento de su comercio con los países del MCCA. Todo esto, sin embargo, no se ha materializado en su incorporación definitiva al programa centroamericano de integración. ${ }^{\prime}$

Con el propósito de conocer los beneficios que podría obtener Panamá de su integración con el MCCA, se analizan aquí algunas características distintivas de la economía panameña, se examinan las áreas en las cuales la integración podría tener repercusiones positivas y se cuantifica el efecto que tendría un régimen de libre comercio con el MCCA en el sector externo panameño.

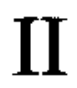

\section{La economía panameña}

La estructura económica de Panamá muestra una alta participación del sector servicios en su producto interno bruto (aproximadamente $80 \%$ a principios de los años noventa). Esa tendencia se ha venido acentuando en los últimos años, particularmente en el transporte, el almacenamiento y las comunicaciones, en tanto que se ha contraído la participación de la agricultura y la industria (cuadro 1 y gráfico 1 ).

La inversión también ha disminuido su participación en el PIB. La inversión pública ha bajado sostenidamente desde 1976, hasta llegar a una cuarta parte del valor de ese año en 1992. La inversión privada también descendió entre 1974 y 1991 y el repunte alcanzado en 1992 ś́lo la llevó a una cifra inferior a los valores acusados a principios de los

$\square$ El autor agradece los valiosos comentarios de lris Alvarez, Gilberto Chona, Oscar A. Núñez-Sandoval, Javier León, Luis Amado Sánchez y Ernesto Stein. Los puntos de vista expuestos en este trabajo son estrictamente personales. años setenta. La participación en el PIB de la inversión privada en construcción, en maquinaria y equipo y en equipo de transporte tendió a disminuir desde principios de los años setenta, mostrando una recuperación en los noventa (gráficos 2, 3 y 4).

Cabe mencionar que la inversión en maquinaria y equipo ha sido identificada como la que ejerce el mayor impacto sobre el crecimiento económico, genera sustanciales beneficios de externalidades (De Long y Summers, 1991) y tiene una rentabilidad social mayor que su rentabilidad privada, por lo que las políticas que la impulsan a niveles superiores a Ios valores de laissez-faire conducen a acelerar el crecimiento económico (De Long y Summers, 1992). Asimismo, el precio de la inversión en maquinaria y

\footnotetext{
1 Véase una reseña de los estudios sobre las relaciones de Panamá con el MCCA referidas a la integración económica en Thoumi (1994). Véase también Salazar-Xirinachs (1990); Lachman, Olaso y Vallarino (1991), y Lachman, Chocano, Figge y González (1992).
} 
equipo ejerce un impacto negativo sobre el crecimiento, por lo que su incentivo por medio de la política tributaria contribuye a incrementar la tasa de crecimiento económico (Jones, 1994). Otros autores han encontrado evidencia empírica de que la inversión en capital fijo, así como los gastos en investigación y desarrollo, tienen efectos tanto o más significativos que los precios relativos en la competitividad de las exportaciones (Magnier y ToujasBernate, 1994).

Por otra parte, la participación de las exportaciones en el PIB mostró una tendencia ascendente entre 1970 y 1980 , al pasar de 38 a $44.03 \%$, pero bajó a $35 \%$ en 1992. La participación de las importaciones

CUADRO I

Panamá: Estructura del PIB (Porcentajes)

\begin{tabular}{|c|c|c|c|c|c|c|}
\hline Sector & 1970 & 1975 & 1980 & 1985 & 1990 & 1993 \\
\hline Agricultura & 9.55 & 7.80 & 6.07 & 6.11 & 6.90 & 5.52 \\
\hline $\begin{array}{l}\text { Industria } \\
\text { manufacturera }\end{array}$ & 12.53 & 11.50 & 10.49 & 8.96 & 9.30 & 9.29 \\
\hline Comercio & 15.84 & 14.34 & 14.77 & 12.57 & 11.69 & 11.87 \\
\hline $\begin{array}{l}\text { Transporte, } \\
\text { almacenamiento } \\
\text { y comunicaciones }\end{array}$ & 6.02 & 9.08 & 22.08 & 25.62 & 25.30 & 25.47 \\
\hline Zona Libre de Colón & 2.15 & 2.35 & 4.79 & 3.20 & 5.54 & 8.61 \\
\hline $\begin{array}{l}\text { Establ. financieros, } \\
\text { seguros y servicios } \\
\text { a empresas }\end{array}$ & 12.01 & 13.99 & 13.08 & 14.16 & 14.22 & 14.87 \\
\hline
\end{tabular}

Fuente: Estadística panameña, Ditección de Estadística y Censo de la Contraloría General de la Repúbtica de Panamá, varios números.

GRAFICO 1

Panamá: Participación del sector transporte, almacenamiento y comunicaciones y de la industria manufacturera en el producto interno bruto

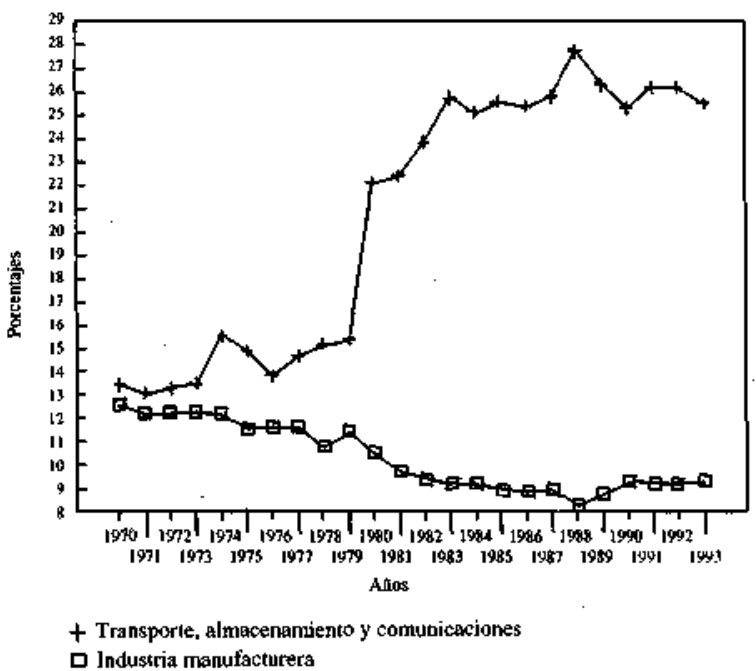

GRAFICO 2

Panamá: Participación en el producto interno bruto de la inversión privada en construcción

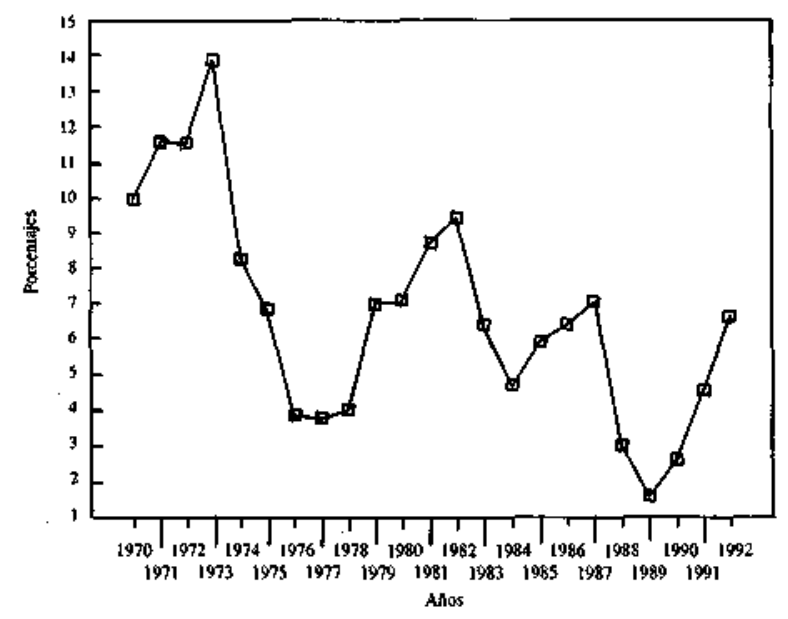

Fuente: Estadistica panameria, Dirección de Estadística y Censo de la Contraloría General de la República de Panamá, varios números. 
GRAFICO 3

\section{Panama: Participación en el producto interno bruto de la inversión privada en maquinaria y equipo}

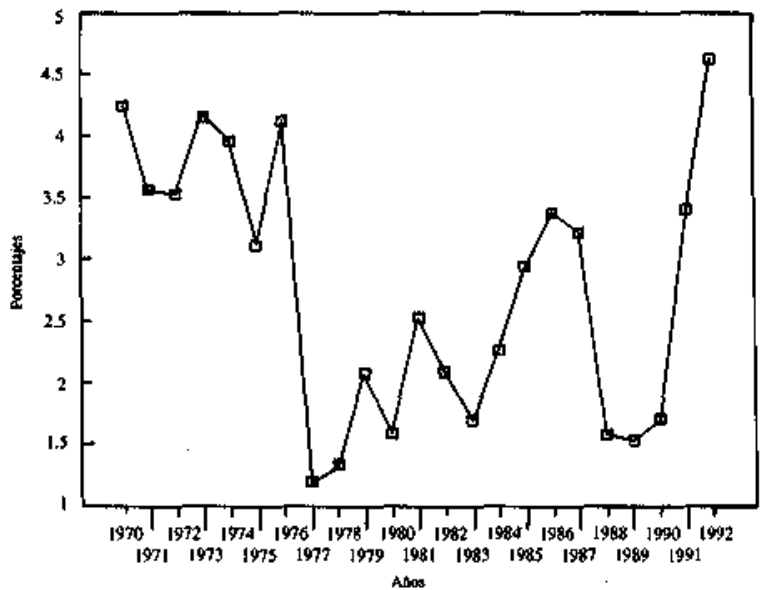

Fuente: Estadística panameña, Dirección de Estadística y Censo de la Contraloría General de la República de Panamá, varios números.

también creció entre 1970 y 1980 (de 41.33 a $47.35 \%$ ), aun cuando en 1992 se redujo a $36.36 \%$.

La estructura económica de Panamá puede explicarse como resultado de un proceso que en la literatura económica se denomina el síndrome holandés. ${ }^{2}$ Este se refiere al efecto desindustrializante, y en algunos casos adverso a la agricultura, que tiene en la economía interna un auge exportador. En Panamá habría que considerar el papel desemperfado por la Zona
ORAFICO 4

\section{Panamá: Participación en el producto Interno bruto de la inversión privada en equipo de transporte}

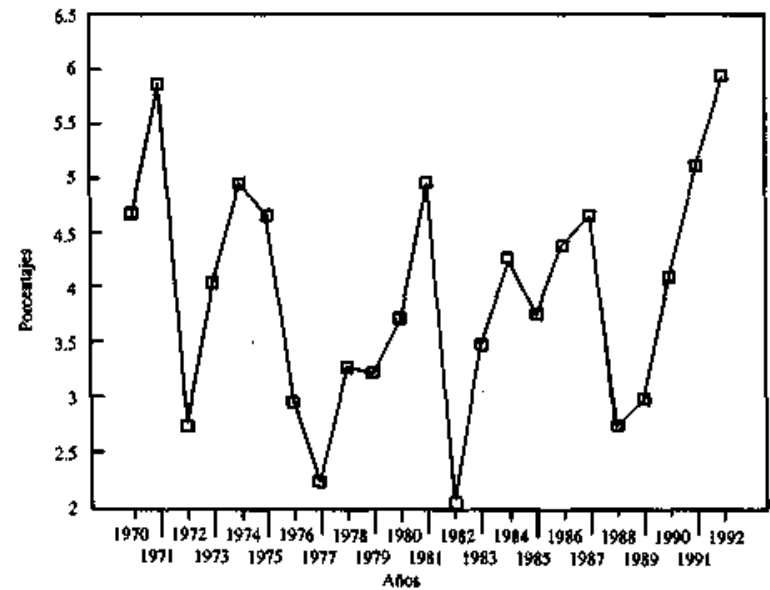

Fuente: Estadística panameña, Dirección de Estadística y Censo de la Contraloría General de la República de Panamá, varios números.

del Canal y más recientemente por la Zona Libre de Colón, las cuales han originado importantes incrementos de ingreso. En efecto, en 1988-1990 las mercancías representaron $22.7 \%$ de las exportaciones totales de bienes y servicios, mientras que el rubro transporte alcanzó al $34.8 \%$ y, dentro de éste, el peaje del Canal equivalió al $19.7 \%$. Por su parte, a la Zona Libre de Colón correspondió el $18.1 \%$ de las exportaciones.

\section{III}

\section{El auge exportador y la economía panameña}

Para apreciar el proceso de desindustrialización de Panamá se presenta aquí un modelo que considera la economía dividida en tres sectores: el sector en auge (A), que puede ser la actividad de la Zona del Canal o de la Zona Libre de Colon; el sector rezagado manufacturero o agrícola $(R)$, y el sector de bienes no transables o de servicios (N). En cada uno de ellos la producción está determinada por los factores capital, recursos naturales y mano de obra. Este último se desplaza, buscando igualar los salarios en los tres sectores mencionados.

2 Véase Gregory, 1976; Corden y Neary, 1982; Corden, 1984; Enders y Herbeg. 1983. Por su parte, Cuddington (1989) reseña la experiencia de varios países en desarrollo.
Se supone que el auge en A eleva los ingresos de quienes representan los factores utilizados en tal sector, lo cual a su vez tiene dos efectos: el efecto gasto y el efecto traslado de recursos (Corden, 1984). Por el lado del efecto gasto, como consecuencia del auge en A se estimula la demanda en el sector de servicios $\mathrm{N}$, con lo cual aumentan los precios, se incentiva la producción de bienes no transables y la mano de obra es atraída desde los sectores A y R; tal desplazamiento de la mano de obra merma la producción del sector $R$. Esto se aprecia en el gráfico 5 , cuyo eje vertical indica el precio relativo del bien no transable en relación con el del bien transable, y cuyo eje horizontal muestra la producción de servicios. La 
curva de oferta se deriva de la función de trasformación entre $\mathrm{N}$ y los dos sectores de bienes transables. La curva de demanda muestra la demanda de servicios a sus distintos precios. El efecto ingreso desplaza la curva de la demanda de $D_{0}$ a $D_{1}$, lo cual aumenta el consumo de servicios de $Q_{0}$ a $Q_{1}$ y el precio de los servicios de $P_{0}$ a $P_{1}$. El alza en el precio de los servicios atrae mano de obra del sector rezagado $y$ reduce la producción de $R$.

\section{GRAFICO 5 \\ Panamá: Representación del síndrome holandés}

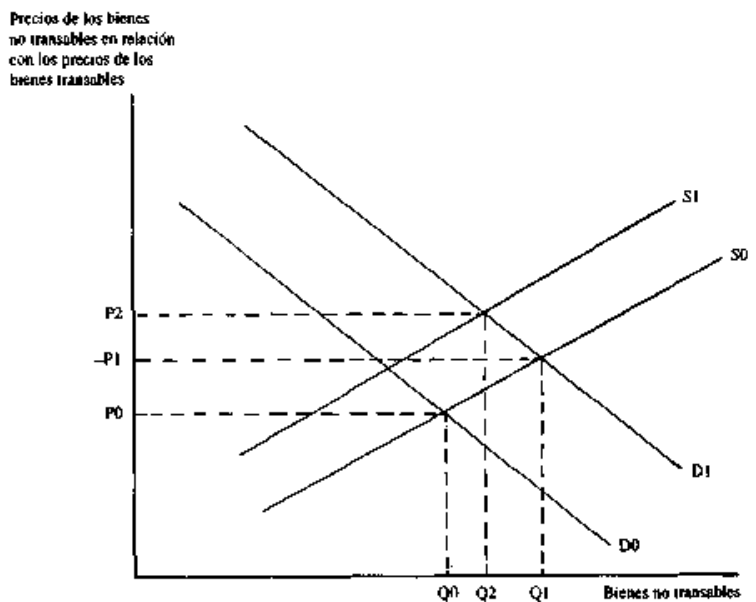

Fuente: Elaboración propia,

El efecto traslado de recursos se debe al aumento de la demanda de mano de obra en A, por el cual ésta se desplaza desde $\mathrm{R}$ y $\mathrm{N}$ hacia $\mathrm{A}$. La salida de mano de obra del sector $R$ da pie a una reducción adicional de la producción de este sector, la que se ha denominado desindustrialización directa. A su vez, el movimiento de mano de obra desde el sector servicios hacia A genera un exceso de demanda de servicios, lo que se representa en el gráfico 5 con el movimiento de la curva de oferta de $S_{0}$ a $S_{I}$. Este incremento de la demanda ocasiona una nueva alza en el precio de los servicios de $P_{1}$ a $P_{2}$, y esto a su vez motiva una salida adicional de mano de obra del sector rezagado hacia el sector servicios. Así, la contracción del sector rezagado se acentúa. La combinación del efecto gasto con el efecto traslado de mano de obra de $\mathrm{R}$ a $\mathrm{N}$ da lugar a una desindustrialización indirecta, que se suma a la desindustrialización direc- ta causada por el movimiento de mano de obra del sector rezagado al sector en auge.

Por otra parte, la rentabilidad en los sectores A y $\mathrm{N}$ aumenta a raíz del incremento de la producción, mientras que decrece en $\mathbf{R}$. La menor rentabilidad del sector rezagado desincentiva la inversión en él, la que es atraída hacia $\mathrm{N}$.

En el modelo se estima que tanto la producción agropecuaria como la industrial se reducen aun en condiciones de desempleo, si se supone que el movimiento de la fuerza de trabajo afecta la mano de obra especializada. Si se supone que el sector en auge no atrae mano de obra de los otros sectores, el efecto de traslado de recursos no ocurriría. El efecto gasto sí se manifestaría, producto del aumento de los precios de $N$, con lo cual se revaluaría la tasa de cambio real y se provocaría la consiguiente reducción de $\mathbf{R}$. En este caso, el efecto gasto también podría materializarse mediante el incremento del consumo del sector público a raíz de una posible mayor recaudación fiscal, consecuencia del auge en $\mathrm{A}$.

Cabe señalar que la expectativa de continuidad del auge económico podría dar lugar a una tendencia a gastar más allá de los medios de la economía. Esto no sólo acentuaría la contracción de los sectores industrial y agrícola sino que podría crear una situación crónica de baja tasa de ahorro, déficit en cuenta coriente y endeudamiento externo.

Aunque el modelo del síndrome holandés no analiza las repercusiones sobre la demanda y la oferta de crédito, el incremento en la demanda de bienes del sector $\mathrm{N}$ podría elevar la demanda de crédito para financiar la producción de dicho sector. Así, el posible financiamiento al sector $\mathrm{R}$ se desplazaría a $\mathrm{N}$ y esto acentuaría la contracción del primero. En Panamá, el crédito a los sectores agrícola e industrial representa 4\% del total (Loehr, 1991).

Además, en vista de la tendencia contractiva, el sector rezagado podría demandar protección, ante lo cual se podría aplicar una serie de medidas para inhibir la competencia. En efecto, en Panamá ha existido un rígido sistema de cuotas, aranceles aduaneros y precios de garantía. Esto ha contribuido a que los precios de varios productos agrícolas estén hasta tres veces por encima del promedio centroamericano (Loehr, 1991). La protección arancelaria a la industria manufacturera, ponderada por la producción, ha sido en promedio de $66.8 \%$; la protección efectiva ha sido mucho más alta, ya que los insumos industrializados han estado exentos de derechos aduaneros. De hecho, Panamá tiene aranceles aduaneros más altos y 
más dispersos que los países del MCCA (Loehr 1991). Según Thoumi (1994), Panamá ha sido uno de los países más proteccionistas del continente.

Por otra parte, la alta protección podría explicar la concentración en la estructura manufacturera, pero a la vez esta última podría llevar a una alta concentración, ya que en varios países se observa que, a mayor concentración industrial, más intensas son las campañas que reclaman protección (Connolly y de Melo, 1994).

Cabe señalar que el auge exportador de Panamá no es necesariamente negativo. Por el contrario, sus bondades se han manifestado en los altos ingresos per cápita, el nivel de desarrollo social y las tasas de crecimiento. Sin embargo, ante los avances internacionales hacia la liberalización económica, el mantenerse al margen de una importante fuente de beneficios derivados de la producción industrial podría representar para el país un alto costo de oportunidad. Cabe destacar que la actividad manufacturera se ha reconocido como generadora de cambios tecnológicos que benefician a la economía como un todo, específicamente por la reducción de costos, mejoras de calidad y adquisición de nuevas destrezas. La expansión del sector servicios, en cambio, ha sido objeto de crítica por cuanto no permite el desarrollo cultural, técnico e intelectual que sólo una industria manufacturera vigorosa y sana, y la urbanización asociada a ella, pueden brindar (Kaldor, 1981). También se ha señalado que una economía acostumbrada a recibir un flujo de rentas corre el riesgo de ser incapaz de generar sus propios ingresos cuando la fuente de esas rentas desaparece (Ellman, 1981).
Por otra parte, estudios recientes han mostrado que la expansión del sector servicios no genera crecimiento económico (Dutt y Lee, 1993). En particular, Harry Johnson (1976) ha manifestado su pesimismo acerca del éfecto del sector financiero en la economía de Panamá. De allí la importancia de fortalecer su sector productivo y a la vez subsanar las restricciones impuestas por el síndrome holandés.

En otras palabras, sería conveniente dar una nueva orientación a la economía panameña, tanto para contribuir a que supere el proteccionismo y el estancamiento de su sector productivo, como para que aproveche los beneficios de la competencia y la productividad. Panamá no debe quedarse al margen de los movimientos integracionistas que han surgido en la subregión. Estos, basándose en un regionalismo abierto, buscan fomentar la eficiencia a través de la competencia y la concertación subregional, y son medios efectivos para lograr una mejor inserción en la economía internacional (CEPAL, 1994; Fuentes, 1994).

Por tal razón, para que el pás aproveche plenamente la ventaja comparativa de su ubicación geográfica, tendrá que adoptar una serie de medidas que doten a su aparato productivo de competitividad y capacidad de innovación. Esta modernización de la economía nacional no sólo se traduciría en un incremento más rápido de la productividad, sino también en la consolidación y ampliación del papel de Panamá como centro internacional. A continuación indagaremos si la integración con el MCCA puede ser un medio efectivo para impulsar la modernización de la economía panameña.
La integración subregional podría complementar y hacer más sustentable la reforma estructural que sería necesaria en Panamá, y a la vez contribuir a la modemización productiva, el avance social y el desarrolo del sector exportador del país.

Se ha visto que el comercio entre miembros de esquemas de integración es básicamente de carácter intraindustrial (Balassa y Bauwens, 1987; Cáceres, 1994). También que esta modalidad de comercio ocure por la similitud en los niveles de ingreso per cápi- ta y de PIB de los países miembros (Forster y Ballance, 1991: Greenaway, Hine y Milner, 1994). Asimismo, según el análisis de la teoría de las uniones aduaneras, la creación de comercio en un esquema de integración será mayor cuanto más similares sean los países que lo conforman (El-Agra, 1989), y si los países que participan en el esquema mantienen ya importantes relaciones comerciales (CEPAL, 1994). El esquema de integración cuyos miembros acusan niveles de PIB similares a los panameños es el MCCA, y varios de sus 
países miembros tienen importantes nexos comerciales con Panamá. Por lo tanto, la vinculación de éste con el MCCA podría serle más provechosa para la generación de comercio. 3

La integración con el MCCA también le aseguraría a Panamá un mercado ampliado, que no existiría si el país optara por una liberalización comercial unilateral. ${ }^{4}$ Específicamente, el MCCA ofrecería a Panamá, en condiciones de reciprocidad, un mercado de 22 millones de personas, que facilitaría sus exportaciones. Esto reviste especial importancia, dada la alta variabilidad de la relación de precios del intercambio de Panamá (Leamer, Guerra, Kaufman y Segura, 1995); para su estabilización estos autores recomiendan la exportación de manufacturas, lo cual haría posible el mercado ampliado centroamericano. La relación del intercambio también mejoraría porque Panamá podría vender sus productos a precios "protegidos" en virtud del arancel externo común, en tanto que los países que exportan al MCCA y a Panamá podrían verse obligados a bajar sus precios para mantenerse competitivos. 5

En el MCCA, la ampliación del mercado en virtud de la integración dio lugar a aumentos en la inversión privada (Cline, 1978). De hecho, la reformulación reciente de la teoría del gran impulso (Big $P$ ush) en el marco de una competencia imperfecta (Murphy, Sheleifer y Vishny, 1989) señala que las inversiones simultáneas en diferentes sectores de un país generan mercados recíprocos, incrementando simultáneamente la demanda de productos de estos sectores, de forma tal que las empresas pueden obtener ganancias que no se lograrían sin ese conjunto de inversiones. Esta complementariedad de la demanda efectiva, que se vincula al tamaño del mercado, puede materializarse en un marco subregional mediante la integra-

3 Forster y Ballance (1991) señalan: "La magnitud de la especialización y del comercio intraindustrial tiende a ser mayor entre países similares en términos de tamaño o niveles de renta. Además, a más alta renta per cápita y mayor tamaño de mercado se incrementa el grado de especialización intraindustrial para la mayor parte de las industrias". Cáceres (1994), por su parte, analiza las corrientes de comercio intraindustrial en el caso de la integración centroamericana.

4 Al considerar un esquema de apertura comercial unilateral para Panamá cabe recordar lo que se pregunta Dornbusch (1989): "....se sugiere que Argentina pase a una posición unilateral de libre comercio. ¿Qué industria sobrevivit́a?, ¿y cae semejante resultado dentro del ámbito de lo políticamente aceptable? Si este no es el caso, una unión aduanera puede ser una alternativa muy importante para disminuir los costos de la protección".

5 Wonnacott y Wonnacott (1981) y Dornbusch (1989) analizan el tema de la relación de precios del intercambio en un esquema de integración económica. ción. Así, la proximidad geográfica de Panamá a los países del MCCA le permitiría recibir el desborde de las inversiones de esos países y así sustentar un efectivo esfuerzo de formación de capital.

Además, la integración con el MCCA prepararía a Panamá para la posible integración futura con mercados más desarrollados - por ejemplo, con el surgido del Tratado de Libre Comercio de Norteamérica (TLCN) - y le serviría de aprendizaje para desarrollar ventajas competitivas que, con el tiempo, le permitirían adherir con éxito a otros bloques economicos. ${ }^{6}$

Por otra parte, la ampliación del mercado se traduciría en una disminución de la concentración industrial, ya que prevalecería la concentración de empresas en el mercado a nivel centroamericano. Esto facilitaría la exportación, debido a la relación inversa entre la concentración industrial y el margen de los precios sobre los costos (Sleuwaegen y Yamawaki, 1988; Forster y Balance, 1991). De hecho, a la integración económica se le ha atribuido un efecto estimulante, ya que una mayor competencia incentiva esfuerzos adicionales de los empresarios y gerentes (Pelkmans, 1982). A la vez, la integración reduce los costos de producción e incrementa la productividad de las empresas (Venables, 1994). En el caso centroamericano, la integración ha contribuido a disminuir las presiones inflacionarias a través de la competencia (Cáceres, 1978). Además, los cálculos de los efectos dinámicos de la integración, en términos de mayor eficiencia, incremento del ahorro y economías de escala, muestran que éstos son significativos en la CEE (Péres, 1993). Lo expuesto indica que la integración es un medio eficaz para contrarrestar las tendencias al estancamiento asociadas al síndrome holandés.

Lo que puede hacer la integración para mitigar los efectos nocivos de ese síndrome se puede apreciar en el gráfico 6 que, por consideraciones de brevedad, presenta sólo el funcionamiento del efecto gasto. En dicho gráfico el salario en el mercado laboral $W$ se presenta en la ordenada y la oferta de mano de obra OsOt en el eje horizontal. El insumo de mano de obra del sector servicios es representado por la distancia desde $O s$, y el del sector manufacturero por la distancia desde $O t$. El cuadrante inferior contiene la función de producción del sector manufacturero, donde la producción $Y$ se corresponde con distintos niveles de mano de obra. La curva $L s$ representa la demanda

6 Cáceres (1993 y 1994) destaca la oportunidad de preparación para un futuro buen desempeño en esquemas de integración con países más desarrollados, postulando la complementariedad entre la integración subregional y la posterior apertura global. 
de mano de obra en el sector servicios, en tanto $\mathrm{Lm}$ se refiere a la demanda de mano de obra en el sector industrial. De la suma de la demanda de mano de obra en el sector industrial y la demanda de mano de obra del sector en auge se obtiene la demanda de mano de obra total del sector exportador, $L t$.

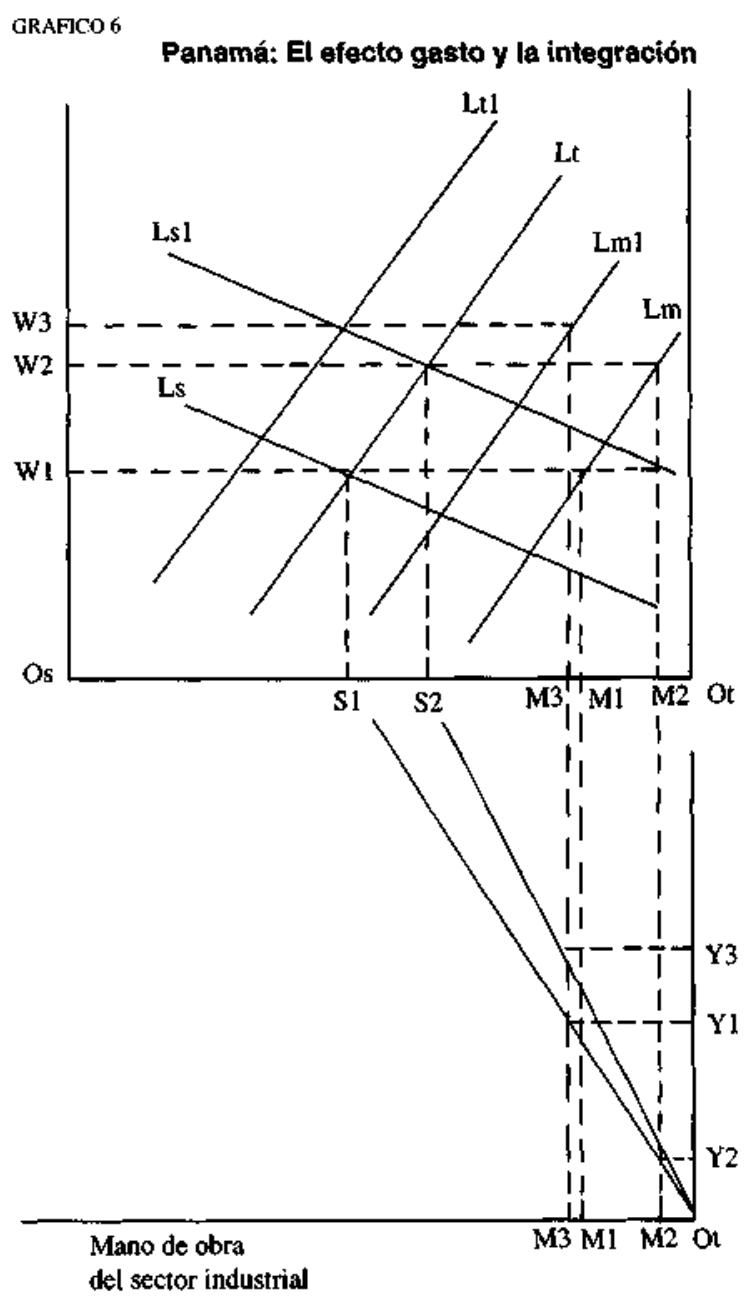

Fuente: Elaboración propia.

Al considerar el efecto ingreso, puede apreciarse en el gráfico cómo el auge exportador da lugar a un aumento en el consumo de servicios; esto estimula la demanda de mano de obra en ese sector, lo que desplaza la curva de $L s$ a $L s 1$. El equilibrio se restablece a un salario $W_{2}$. Con este salario, el empleo en servicios aumenta de $S_{1}$ a $S_{2}$ y el empleo en la industria disminuye de $M_{1}$ a $M_{2}$. Esto último da lugar a una contracción de la producción industrial de $Y_{1}$ a $Y_{2}$.

$\mathrm{Si}$ el país ingresa al MCCA, se incrementará la productividad de la mano de obra en el sector industrial. Este aumento en la producción marginal del trabajo se representa en el gráfico por el desplazamiento de la curva $L m$ hacia $L m$, lo que a su vez produce que la curva $L t$ se desplace hacia $L t$. El nuevo equilibrio se establece a un salario $W_{3}$, que ocasiona una reducción del empleo en servicios y un incremento del mismo en la industria, de $M_{2}$ a $M_{3}$. En consecuencia, la producción industrial aumenta de $Y_{2}$ a $Y_{3}$. Se observa, entonces, que la integración ha aumentado tanto la producción como el empleo industrial en $Y_{2}$ $Y_{3}$ y $M_{2} M_{3}$, respectivamente, contrarrestando así los efectos del síndrome holandés.

Por otro lado, la integración ofrecería a Panamá, como beneficio adicional, un incentivo más para mantener la disciplina macroeconómica. En efecto, la liberalización económica en el marco multilateral (subregional) sería más efectiva que a nivel nacional, por la disciplina y el cumplimiento riguroso que motiva el seguimiento multilateral (Wolf, 1986; Genberg y De Simone, 1993). Asimismo, la reforma en un marco subregional generaría más credibilidad, y ésta, más la sustentabilidad, son determinantes del éxito de los programas de reforma (Rodrik, 1990 y 1991; Funke, 1993). Además, facilitaría el acceso de Panamá al acervo de experiencias de los países del MCCA en materia de reforma económica, así como su participación en un esfuerzo de transformación productiva. Este podría costarle menos gracias a lo que han vivido ya esos otros países, y al apoyo internacional que el programa centroamericano de integración ha recibido. Además, la proximidad geográfica de Panamá a los países del MCCA estimularía las exportaciones panameñas; de hecho, la distancia y el costo de transporte han sido identificados como las variables que más inhiben el comercio intralatinoamericano (Primo Braga, Safadi y Yeats, 1994). Además, la integración, por el impulso que daría a las exportaciones, sería efectiva para mitigar los efectos adversos del ajuste estructural. ${ }^{7}$

Para Panamá, la integración económica con los países del MCCA constituiría un "trueque de mercados" entre países de similares niveles de desarrollo,

\footnotetext{
7 Greenaway y Hine (1991) argumentan que en la CEE los costos del ajuste econónico han sido atenuados por la integración comercial. Es del caso señalar que en El Salvador, la Fundación Salvadoreña para el Desarrollo Económico y Social (FUSADEs, 1991) efectuó una encuesta a 323 empresas en noviembre de 1991, las cuales respondieton sobre beneficios de la integración centroamericana de la siguiente manera: más exportaciones (21.1\%); importaciones más baratas $(53.9 \%$ ); posibilidad de inversión en la subregión (17.0\%); ninguna ventaja (15.2\%); otros (10.5\%).
} 
lo que junto con el arancel externo común le permitiría mantener su cuenta comercial a niveles manejables. Esto dista de la apertura unilateral, en donde la falta de reciprocidad en la preferencia arancelaria y la asimetría con el resto del mundo pueden conducir a un severo deterioro de la cuenta comercial. Esto es precisamente lo que ha ocurrido en la región desde
1989 , cuando se dio inicio a la mayoría de las liberalizaciones comerciales (Gana, 1994). Lo que debe destacarse es que para el financiamiento del déficit comercial es posible que se necesiten tasas de interés muy elevadas que atraigan capital externo, con lo cual la economía podría experimentar una contracción o tender al estancamiento (gráfico 7).
(1)

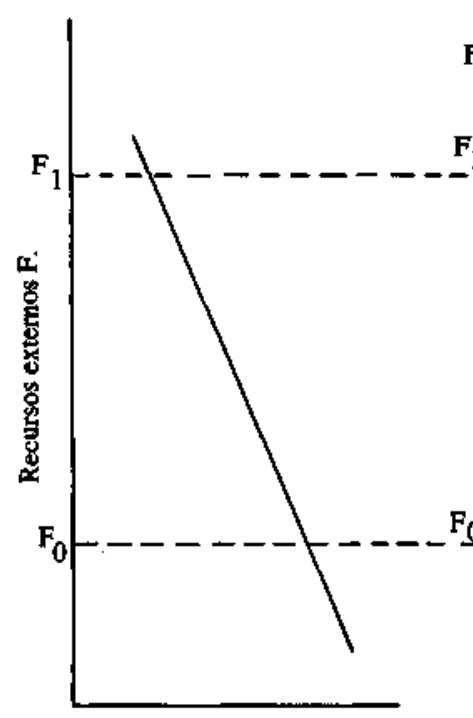

Arancel aduanero
(2)

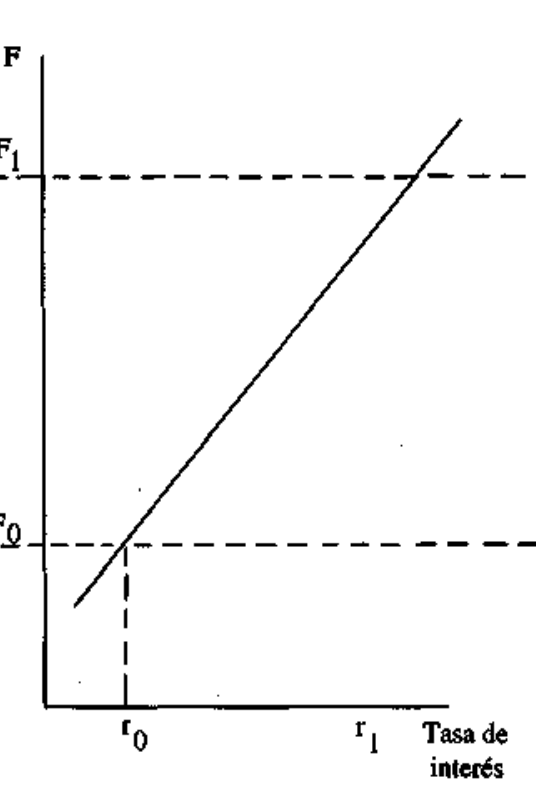

(4)

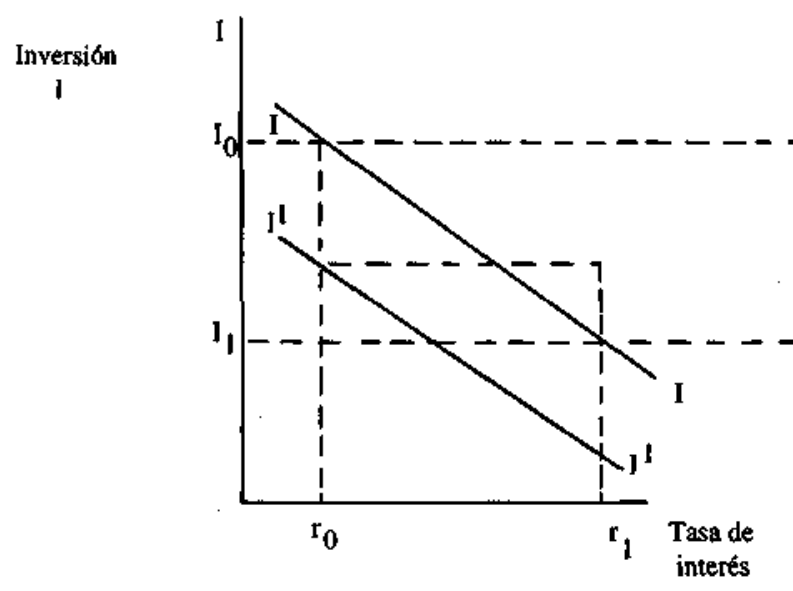

(3) 
En el cuadrante 1 de dicho gráfico se muestra la relación inversa entre déficit comercial y nivel del arancel aduanero. Inicialmente, para financiar el déficit comercial se requiere la entrada de recursos externos $F_{0}$, la que se obtiene ofreciendo una tasa de interés $r_{0}$, como se ve en el cuadrante 2 . En el cuadrante 4 se muestra el nivel de inversión $I_{0}$ que corresponde a la tasa de interés $r_{\mathrm{o}}$. Esta inversión da lugar, a través del multiplicador, a un nivel de producto $Y_{0}$, que aparece en el cuadrante 5. Cuando hay una rebaja arancelaria se puede notar que por el mayor déficit comercial resultante se necesitará una mayor entrada de recursos externos $F_{1}$, que se obtendría a una tasa de interés más alta $r_{\mathrm{l}}$, e implicaría una menor tasa de formación de capital $I_{1}$, y menor producto $Y_{1}$. En el cuadrante 3 se observa que en estas condiciones hay una relación inversa entre entrada de recursos externos y producto interno bruto, por cuanto los recursos externos sostienen una economía en contracción y con decreciente tasa de formación de capital. Además, la mayor necesidad de recursos externos se traduciría en una creciente deuda externa, que ante niveles estancados de PIB podría implicar el deterioro de los índices de solvencia. El proceso anterior se puede describir como irreversible. Esto ocurre cuando al restituirse el déficit en la cuenta comercial a un valor original $F_{0}$, no se recupera el valor original del producto $Y_{0}$, porque la incertidumbre causada por la recesión habría ocasionado un cambio de estructura en la relación entre inversión y tasa de interés: a la misma tasa de interés, la inversión sería menor que antes. ${ }^{8}$ Esto se muestra en el cuadrante 4 como el desplazamiento de la curva $I I$ a $I^{1} I^{1}$. Se puede apreciar que si el đéficit comercial se redujera al valor $F_{0}$, el producto se recuperaría al valor $Y_{2}$, inferior al nivel inicial $Y_{0}$.<smiles>[AlH]</smiles>

\section{Hacia una agenda regional de reforma}

\section{estructural en el marco de la integración}

La integración de Panamá con el MCCA debería ser un proceso gradual que permitiera aprovechar beneficios en determinadas áreas y fomentar en el mediano plazo un marco de libre comercio. Esto significaría establecer un programa de desgravación generalizado que se aplicaría a una gama creciente de productos. Los actuales tratados comerciales entre Panamá y el MCCA no promueven la competencia; por el contrario, como lo señala Thoumi (1994), son verdaderos instrumentos proteccionistas resultantes de la colusión entre los productores de ambas partes, que comparten los mercados de acuerdo a sus regulaciones. Dicho autor también indica que esta modalidad de comercio refleja intercambios entre sucursales de empresas transnacionales sobre la base de un comercio negociado. De allí la conveniencia de avanzar gradualmente hacia el libre comercio con el MCCA y establecer, frente al resto del mundo y mientras se consolidan las reformas requeridas, una protección menor que la actual. Sin la protección mínima necesaria frente a países desarrollados, los déficit comerciales resultantes obligarían a adoptar altas tasas de interés internas para atraer capitales extranjeros que contribuyesen a fi- nanciar dicho déficit. El elevado costo del capital conduciría al estancamiento de la inversión privada y por ende a la pérdida de credibilidad de las reformas macroeconómicas, lo que acentuaría la contracción.

Panamá, por su excelente dotación portuaria y por ser un importante centro financiero internacional, ofrece ventajas especiales en el sector servicios. De allí que su integración con el MCCA podría descansar en este sector. Sin embargo, el costo del transporte marítimo en Panamá es sumamente elevado, por lo que no habría mayores incentivos para que los países del MCCA usaran las instalaciones panameñas. Además, el transporte terrestre de Panamá también tiene un costo más alto que el de otros países del Istmo y posee una rígida estructura oligopólica (ROCAP, 1987). Podría estructurarse un programa conjunto de integración y desregulación del sector servicios para promover la competencia, con miras a que la integración

\footnotetext{
8 Pyndyck y Solimano (1993) analizan el impacto negativo que el riesgo y la falta de credibilidad tienen sobre la inversión. El cambio estructural que ocurre a raiz de la persistencia de choques se examina en Cáceres (1985 y 1991).
} 
sea factible y provechosa. En este programa sería prioritaria la implementación de políticas de competencia nacional y subregional.

Para efectuar un cambio estructural en la economía panameña no puede recurrirse exclusivamente a reformas de políticas. Habría que actuar también en otros campos, especialmente la promoción de exportaciones, la difusión y adaptación tecnológicas y la formación de cuadros técnicos y gerenciales de alta calidad. En efecto, el crecimiento impresionante de los países asiáticos en desarrollo ha radicado en la adopción de políticas que fortalecen tanto el funcionamiento del mercado como el del Estado y cuya conjunción permite un marco económico-institucional que impulsa la equidad y la competitividad internacional (Lim, 1994). La protección en esas economías no ha sido desmedida, sino que ha servido para suplir la ausencia del mercado en algunos casos, y facilitar su mejor funcionamiento en otros. Se han establecido esquemas de protección transparentes, se ha capacitado a los recursos humanos, se ha apoyado el desarrollo de nuevas tecnologías, se ha aplicado reformas fiscales y se ha proporcionado información sobre mercados. Además, la coordinación de la inversión privada mediante subsidios ha descansado en cuadros profesionales del sector público de alto nivel técnico, lo que ha hecho que las intervenciones estatales hayan tenido éxito (Rodrik, 1995).

Dada la importancia de efectuar cambios estructurales convendría que Panamá impulsara, junto con los países del MCCA, una estrategia subregional para la reforma económica y social. Esta estrategia podría llevarse a cabo mediante esfuerzos conjuntos que facilitarían la cooperación intrarregional e internacional, el intercambio de experiencias, y un avance armónico en las reformas nacionales que haga verdaderamente integrables las economías nacionales y las aproxime a la integración con otras regiones. Un caso relevante es el de Chile, cuya trayectoria de importantes reformas económicas es reconocida como un avance que facilitaría su integración al TLCN (The Economist, 25 de febrero al 3 de marzo de 1995, p. 29).

Esta estrategia implicaría establecer con claridad los objetivos que cada país quiere lograr con la integración, e identificar las medidas de reforma que es necesario aplicar para alcanzar un sistema productivo y social armónico con los de la subregión y con otros esquemas, como el TLCN o el Pacto Andino, por ejemplo. Implicaría también diferenciar las medidas de alcance nacional, subregional e internacional; establecer un calendario para cada acción, diferenciado por país, y señalar a los encargados de llevarlas a cabo. La estrategia podría ser formulada por el Gabinete Económico Centroamericano, el que también podría estar a cargo del seguimiento de su ejecución. En este marco, cada país identificaría el alcance nacional de la reforma, programaría las acciones correspondientes y se aseguraría de que hubiese congruencia con los niveles subregional e internacional. El punto de partida podría ser la elaboración de diagnósticos sectoriales de alcance subregional, que permitieran identificar las reformas necesarias a nivel nacional para alcanzar determinados objetivos y metas de modernización económica en un marco de armonización regional e internacional. Las medidas que deriven de los diagnósticos regionales serían aplicadas a nivel nacional, conforme a lo que haya que hacer en cada país y según su respectivo calendario. En la ejecución de las acciones de reforma nacionales se haría hincapié en la eliminación de obstáculos a la integración regional e internacional. Este enfoque también podría ser útil para establecer un diálogo subregional con las fuentes internacionales de recursos y cooperación técnica, así como con países de otras regiones.

Asimismo, al estructurar dicha estrategia los países centroamericanos podrían plantear a los países miembros del TLCN que participaran como observadores en el proceso de transformación económica y social, a fin de ir dialogando con miras a una futura incorporación del Istmo a ese esquema de integración. El marco multilateral de reforma, con la participación de los países miembros del TLCN, otorgaría mayor credibilidad al proceso. Además, el diálogo conjunto aumentaría el poder de negociación de los primeros y podría servir para efectuar reformas de especial importancia en las economías nacionales.

La estrategia multilateral abarcaría la reforma económica y en particular la social, de manera de ir generando las bases de una economía más equitativa, lo que redundaría en consolidar la modernización económica. En algunos países se pondría de relieve el desarrollo social, a fin de subsanar deficiencias históricas y promover la convergencia de los indicadores sociales en el Istmo. Es decir, se haría hincapié en la integración nacional. ${ }^{9}$ En este marco, tiene especial importancia el apoyo al desarrollo del capital humano, ya que este recurso es determinante en la exportación de manufacturas (Wood, 1994; Wood y Berge, 1994; Balassa y Bauwens, 1988).

\footnotetext{
9 Ranis (1993) ha descrito exhaustivamente los requisitos internos para la integración económica regional. Recordemos, por otra parte, que para hacer viable la creación del mercado básico único en 1992 la cEE adoptó ya en 1985 un conjunto de 282 medidas. (Pelkmans, 1991).
} 


\section{VI}

\section{Incremento que mostrarían las exportaciones e importaciones de Panamá hacia y desde el MCCA si fuese miembro de éste}

A fin de estimar cuál podría ser el desempeño de Panamá en el MCCA si fuese miembro de él, se aplicaron modelos econométricos de gravedad. En este tipo de modelos, el comercio entre dos países es función directa de sus respectivas "masas económicas" y de la "fricción de la distancia" entre ambos. ${ }^{10}$

Para representar las "masas económicas" se us6 la cuantía de capital humano de los países exportador e importador ( $H i$ y $H j$, respectivamente) y su correspondiente producto nacional bruto $\left(Y i\right.$ e $\left.Y_{j}\right)$. La "friccion" al comercio fue representada por la distancia en kilometros entre ciudades capitales $(D i j) .{ }^{11}$

Como primer enfoque se estimó una ecuación de corte transversal para explicar las exportaciones intracentroamericanas, excluidas las de Panamá. Con los parámetros de esa ecuación se calcularon los valores de las exportaciones de Panamá hacia los países del MCCA. Las exportaciones así calculadas reflejarían una situación en la que Panamá sería miembro del MCCA; la diferencia entre estas exportaciones esti- madas y las exportaciones reales serían las exportaciones adicionales que Panamá efectuaría si se integrara plenamente al MCCA.

Las ecuaciones estimadas para las exportaciones, $E i j$, no incluyen a Guatemala por no disponerse de información sobre los índices de capital humano en ese país (cuadro 2). Se puede apreciar que ambas ecuaciones confirman que la distancia tiende a atenuar el comercio; y además, que la elasticidad de las exportaciones en relación con el capital humano es mayor que la elasticidad respecto del PIB.

A partir de la ecuación (1) se calcularon los valores de las exportaciones de Panamá hacia cuatro países centroamericanos (cuadro 3). De allí se obtuvo que si las exportaciones panameñas se efectuaran en el régimen del MCCA, ellas alcanzarian la suma de 149 millones de dólares, es decir, aproximadamente tres veces el valor real registrado en 1992. Esto se explica por el nivel relativamente alto del capital humano de Panamá y Costa Rica, su principal socio comercial y vecino más cercano.

CUADRO 2

Istmo Centroamericano, excluidos Panamá y Guatemalu: Modelo de gravedad

\begin{tabular}{|c|c|c|c|c|c|c|c|c|}
\hline \multirow{2}{*}{$\begin{array}{l}\text { Variable } \\
\text { dependiente }\end{array}$} & \multicolumn{6}{|c|}{ Varjables independientes ${ }^{a}$} & \multirow[b]{2}{*}{$R^{2}$} & \multirow[b]{2}{*}{$D W$} \\
\hline & $c$ & $H i$ & Hj & $Y i$ & $Y j$ & Dij & & \\
\hline & $\begin{array}{l}-9.08 \\
(1.45)\end{array}$ & $\begin{array}{c}3.03 \\
(2.90)\end{array}$ & $\begin{array}{c}1.09 \\
(1.05)\end{array}$ & & & $\begin{array}{l}-1.04 \\
(1.28)\end{array}$ & 0.53 & 2.30 \\
\hline (2) $\log E i j$ & $\begin{array}{l}-7.03 \\
(1.61)\end{array}$ & & & $\begin{array}{c}1.27 \\
(4.25)\end{array}$ & $\begin{array}{c}0.28 \\
(0.94)\end{array}$ & $\begin{array}{l}-0.42 \\
(0.98)\end{array}$ & 0.44 & 2.09 \\
\hline
\end{tabular}

Fuente: Elaboración propia. ${ }^{\text {a }}$ Se refiere a los logaritmos de las variables independientes.

${ }^{10}$ Markheim (1994) evalúa la confiabilidad del modelo de gravedad en la estimación de los efectos de la integración sobre el comercio.

"I En este trabajo el índice de capital humano se ha cuantificado como la tasa de matsícula en la escuela secundaria más cinco veces la tasa de matrícula en el nivel terciario. Los índices de capital humano se calcularon sobre la base de datos del Banco Mundjal (1993). Los datos sobre el PIB, el comercio intrarregional y las distancias entre paises fueron tomados de SJECA, varios numeros. 
Panamá: Estimación de sus exportaciones si fuese miembro del Mcca (Millones de dólares)

\begin{tabular}{|c|c|c|c|c|}
\hline $\begin{array}{l}\text { Exportaciones } \\
\text { hacia: }\end{array}$ & $\begin{array}{l}\text { Monto } \\
\text { estimado } \\
\text { usando } \\
\text { ecuación } \\
\quad(1)\end{array}$ & $\begin{array}{l}\text { Monto } \\
\text { estimado } \\
\text { usando } \\
\text { ecuación } \\
\quad \text { (4) }\end{array}$ & $\begin{array}{l}\text { Monto estimado } \\
\text { usando ecuación } \\
\text { (6) }\end{array}$ & $\begin{array}{l}\text { Monto } \\
\text { rea] } \\
(1992)\end{array}$ \\
\hline Costa Rica & 96.54 & 139.00 & 105.6 & 29.1 \\
\hline Nicaragua & 28.22 & 7.35 & 5.5 & 1.4 \\
\hline Honduras & 1.08 & 5.52 & 13.4 & 3.2 \\
\hline El Salvador & 23.10 & 70.30 & 51.9 & 12.3 \\
\hline Guatemala & - & - & 16.8 & 3.9 \\
\hline Total & 148.94 & 222.17 & 193.2 & 49.9 \\
\hline
\end{tabular}

Fuente: Elaboración propia.

Otro enfoque para medir el posible impacto del ingreso de Panamá al MCCA consistió en estimar ecuaciones de corte transversal para las exportaciones de los países del MCCA, y de Panamá al MCCA, e introducir variables cualitativas (dummies) para medir los valores particulares del intercepto $(D I)$ y del coeficiente de la distancia (D2) cuando se aplica el modelo a las exportaciones de este país. Las variables cualitativas resultaron significativas en todas las ecuaciones (cuadro 4). Así, las ecuaciones (3) y
(5) indican que, cuando se trata de las exportaciones panameñas, sus términos constantes son menores en -1.66 y -1.38 , respectivamente. Estos términos negativos podrían interpretarse como una penalización a las exportaciones panameñas por no estar en el marco del MCCA. Por su parte, las ecuaciones (4) y (6) indican que las exportaciones panameñas enfrentan una "fricción" por la distancia más acentuada que la de los países del MCCA, de -0.23 y -0.19 respectivamente.

CUADRO 4 Modelo de gravedad, incluyendo a Panamá, con variables
cualitativas del intercepto (D1) y de la distancia (D2)

\begin{tabular}{|c|c|c|c|c|c|c|c|c|c|c|c|}
\hline \multirow{2}{*}{\multicolumn{2}{|c|}{$\begin{array}{l}\text { Variables } \\
\text { dependientes }\end{array}$}} & \multicolumn{10}{|c|}{ Variables independientes $^{a}$} \\
\hline & & \multirow{2}{*}{$\begin{array}{c}C \\
-11.33 \\
(1.88)\end{array}$} & \multirow{2}{*}{$\begin{array}{r}H i \\
3.16 \\
(3.36)\end{array}$} & \multirow{2}{*}{$\begin{array}{c}H j \\
1.47 \\
(1.92)\end{array}$} & \multirow[t]{2}{*}{$Y i$} & \multirow[t]{2}{*}{$Y j$} & \multirow{2}{*}{$\begin{array}{c}\text { Dij } \\
-1.11 \\
(1.67)\end{array}$} & \multirow{2}{*}{$\begin{array}{c}D I \\
-1.66 \\
(2.17)\end{array}$} & \multirow[t]{2}{*}{$D 2$} & \multirow{2}{*}{$\frac{R^{2}}{0.6 \mathrm{~b}}$} & \multirow{2}{*}{$\frac{D W}{2.32}$} \\
\hline (3) & $\log E i j$ & & & & & & & & & & \\
\hline (4) & $\log E i j$ & $\begin{array}{r}-11.03 \\
(1.83)\end{array}$ & $\begin{array}{c}3.09 \\
(3.29)\end{array}$ & $\begin{array}{c}1.40 \\
(1.81)\end{array}$ & & & $\begin{array}{l}-1.07 \\
(1.56)\end{array}$ & & $\begin{array}{l}-0.23 \\
(2.11)\end{array}$ & 0.60 & 2.29 \\
\hline (5) & $\log E i j$ & $\begin{array}{l}-7.92 \\
(1.93)\end{array}$ & & & $\begin{array}{r}1.33 \\
(4.44)\end{array}$ & $\begin{array}{c}0.46 \\
(1.69)\end{array}$ & $\begin{array}{l}-0.59 \\
(1.45)\end{array}$ & $\begin{array}{l}-1.38 \\
(2.33)\end{array}$ & & 0.62 & 2.15 \\
\hline (6) & $\log E i j$ & $\begin{array}{l}-8.13 \\
(1.98)\end{array}$ & & & $\begin{array}{r}1.33 \\
(4.46)\end{array}$ & $\begin{array}{c}0.46 \\
(1.71)\end{array}$ & $\begin{array}{l}-0.57 \\
(1.36)\end{array}$ & & $\begin{array}{l}-0.19 \\
(2.40)\end{array}$ & 0.62 & 2.16 \\
\hline
\end{tabular}

Fuente: Elaboración propia. ${ }^{a}$ Se refiere a los logaritmos de las variables independientes.

Con estos resultados, se estimó la diferencia que la integración podría significar para las exportaciones panameñas. Para este fin se supuso, primero, que el ingreso de Panamá al MCCA eliminaría los términos negativos adicionales de las constantes de las ecuaciones (3) y (5). Así, sobre la base de la ecuación (3), se calculó que si Panamá ingresara al MCCA sus exportaciones se incrementarían en 5.26 veces, mientras que sobre la base de la ecuación (5) el incremento de las exportaciones sería de 3.97 ve- 
ces $[\text { exp. }(1.38)=3.97 \text { veces. }]^{12}$ Asimismo, por medio de las ecuaciones (4) y (6) se estimó en cuánto aumentarian con ese ingreso las exportaciones de Panamá a los países del MCCA. En estos casos, se supuso que los términos que penalizan las exportaciones panameñas $(-0.23 \log D i j$ y $-0.19 \log D i j)$ no existirían si Panamá fuese miembro del MCCA. En el caso de la ecuación (4), el aumento de las exportaciones panameñas sería de 4.8 veces, mien- tras que con la ecuación (6) el incremento sería de 3.8 veces.

Para calcular las importaciones de Panamá desde el MCCA si el país ingresara a este esquema de integración, en forma análoga a lo que se hizo para las exportaciones, se estimaron ecuaciones para las importaciones panameñas provenientes del MCCA, utilizando las variables cualitativas $D I$ y $D 2$ cuando Panamá es el país importador (cuadro 5)..$^{13}$

CUADRO 5 Modelo de gravedad para las importaciones, especificando a Panamá
con las variables cualitativas del intercepto (D1) y de la distancla (D2)

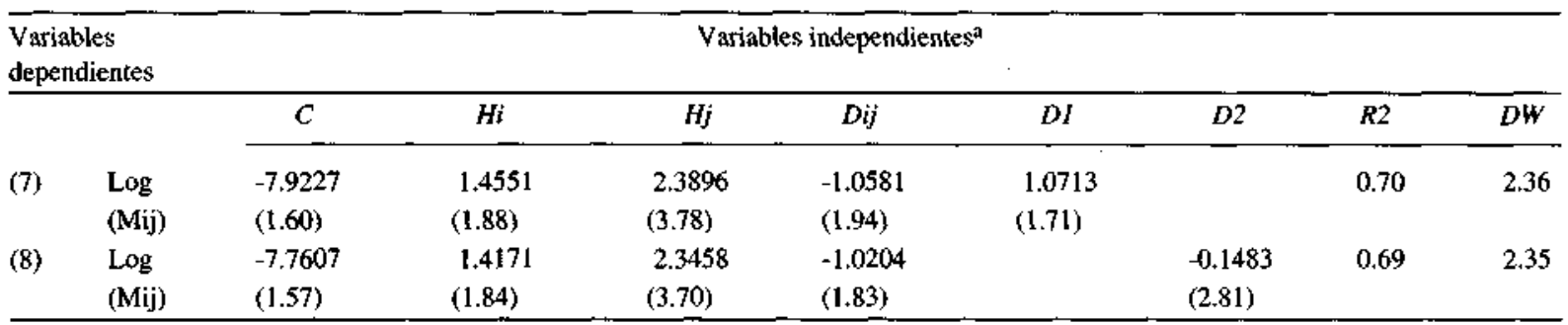

Fuente: Elaboración propia. a Logaritmos de las variables independientes.

La ecuación (7) se empleó para calcular el incremento de las importaciones de Panamá si este país ingresara al MCCA, obteniéndose que el aumento sería de 198 millones de dólares. Este monto es inferior al aumento de 241.96 millones calculado para las exportaciones mediante la ecuación (3). Esto indica que con su incorporación al MCCA, Panamá cerraría su déficit comercial con ese mercado, que fue de 36 millones de dólares en 1992.

Asimismo, sobre la base de la ecuación (8) se calcularon las importaciones panameñas provenientes de cuatro países del MCCA (cuadro 6). Se puede apreciar que con el ingreso a ese esquema de integración ellas alcanzarían a 191.72 millones de dólares. Este

12 Las principales yariables explicativas de las ecuaciones (3) y (5) son las cuantías de capital humano y los tamaños del producto interno bruto, respectivamente, y en ambos rubros Panamá presenta valores relativamente elevados, lo que explica el incremento sustancial que exhibirian las exportaciones panameñas si este país estuviese adherido al MCCA. monto contrasta con el valor estimado de las exportaciones, que fue de 222.17 millones. Así, los modelos estimados indican que Panamá mejoraría su balanza comercial con el MCCA si ingresara a éste.

CUADRO 6

Panamá: Estimación de sus importaciones si fuese miembro del ucca (Millones de dólares)

\begin{tabular}{lcc}
\hline $\begin{array}{l}\text { Importaciones } \\
\text { desde: }\end{array}$ & $\begin{array}{l}\text { Monto } \\
\text { estimado } \\
\text { (ecuación 8) }\end{array}$ & $\begin{array}{l}\text { Ecuación } \\
\text { monto } \\
\text { real }\end{array}$ \\
\hline Costa Rica & 155.36 & $\begin{array}{r}56.7 \\
1.0\end{array}$ \\
Nicaragua & 2.91 & 3.0 \\
Honduras & 9.12 & 7.9 \\
El Salvador & 24.32 & 68.6 \\
Total & 191.72 & \\
\hline
\end{tabular}

Fuente: Elaboración propia.

\footnotetext{
${ }^{13}$ Los resultados no se presentan usando el PIB como variable explicativa porque los coeficientes de determinación y la significancia estadística de los estimadores resultaron ser muy bajos.
} 


\section{VIII}

\section{Consideraciones finales}

La economía panameña ha experimentado auges exportadores que podrían dar lugar a la contracción relativa de los sectores manufacturero e industrial. Esto también contribuiría a la contracción de la inversión y de la exportación de bienes. En ese contexto, la demanda de protección se ha vuelto muy marcada. Esta reacción, incongruente con los movimientos regionales e internacionales hacia la modernización y la competencia, confirma la necesidad de transformar la estructura de la economía panameña.

La integración económica puede ser un mecanismo valioso para ayudar en las tareas de modemización productiva. En primer lugar, el proceso de liberalización económica tendría mayor credibilidad, debido a que existiría un compromiso multilateral en relación con el ajuste; en segundo lugar, el costo de éste podría reducirse por el incremento de las exportaciones, y en tercer lugar, podría estimular la productividad, lo cual constituiría un medio efectivo para contrarrestar los efectos adversos del síndrome hoJandés.

De las distintas opciones de integración que Panamá podría considerar, el programa de integración centroamericano podría ser la más provechosa, dado que la creación de comercio es mayor y el comercio intraindustrial se desarrolla más entre países con niveles similares de PIB y de PIB per cápita. La integración de Panamá con el MCCA debería verse como una acción que acercaría a este país a sus objetivos nacionales, principalmente por la adquisición de experiencia exportadora y el fortalecimiento de su capacidad de competencia, como paso previo para la integración con otros esquemas (por ejemplo, con el TLCN).

La participación de Panamá en un esquema subregional de reforma estructural le permitiría beneficiarse de la experiencia de otros países y tener acceso a la cooperación técnica internacional. Este marco regional de transformación debería abarcar tanto la reforma económica como la social, a fin de consolidar la integración nacional necesaria para sustentar la integración regional.

Estimaciones econométricas muestran que Panamá podría tener un desempeño exportador favorable si ingresara al MCCA, porque este país tiene un capital humano de nivel más alto que los países del MCCA, con la excepción de Costa Rica, y el capital humano es el principal factor determinante de la capacidad de exportación.

\section{Bibliografia}

Balassa, B. y L. Bauwens (1987): Inter-jndustry specialization in a multi-country and multi-industry framework, The Economic Journal, vol, 97, $\mathbf{N}^{\mathrm{o}}$ 388, Cambridge, Reino Unido, Royal Economic Society, diciembre.

(1988): Inter-industry and intra-industry specialization in manufactured goods, Weltwirtschaftiches Archiv. Review of World Economics, Band 124, Heft 1, Tübingen, Institut für Weltwirtschaft Kiel.

Banco Mundial (1993): Informe sobre el desarrollo mundial 1993, Washington, D.C.

Cáceres, L. R. (1978): Integración económica e inflación en Centroamérica: Un modelo espacial, El trimestre económico, vol. XLV, $N^{\circ} 180$, Méxíco D.F., Fondo de Cultura Económica (FCE).

(1985): Ahorro, ínversión, deuda externa y catástrofe, El trimestre económico, vol. LII, $N^{\circ} 207$, México D.F., PCE.

(1991): The determination of the external debt of Honduras, Savings and Development, vol. 15, Milán.

(1993): Ecuador y la integración andina: experiencias y perspectivas, Integración latinoamericana, año $18, \mathrm{~N}^{\circ} 195$, Buenos Aires, Instituto para la Integración de América Latjna (INTAL).
(1994): Costos y beneficios de la integración centroameticana, Revista de la CEPAL, $\mathrm{N}^{\circ}$ 54, LC/G.1845-P. Santiago de Chile, Comisión Económica para América Latina y el Caribe (CEPAL), diciembre.

CEPAL (Comísión Económica para América Latina y el Caribe) (1994): El regionalismo abierto en América Latina y el Caribe, LC/L.808 (CEF. 19/3), Santiago de Chile.

Cline W.R. (1978): Benefits and costs of economic integration in Central America, W.R. Cline y E. Delgado (eds.), Economic Integration in Central America, Washington, D.C., The Brookings Institution.

Connolly, M. y J. De Melo (1994): Protectionism and stagnation: An interpretative history, The Effects of Protectionism on a Small Country, Washington D.C., World Bank.

Corden, W. M. y J. P. Neary (1982): Booming sector and deindustrialization in a small open economy. The Economic Joumal, vol. 92, $\mathbf{N}^{\mathbf{b}} 368$, Cambridge, Reino Unido, Royal Economic Society, diciembre.

Corden, W. M. (1984): Booming sector and Dutch disease economics: Survey and consolidation, Oxford Economic Papers, vol.36, $N^{\circ} 3$, Oxford, Reino Unjdo, Oxford University Press, enero. 
Cuddington J. (1989): Commodity export booms in developing countries, The World Bank Research Observer, vol. $4, \mathrm{~N}^{\circ} 2$, Washington, D.C.. Banco Mundial. julio.

De Long, J. B. y L. H. Summers (1991): Equipment investment and economic growth, The Quarterly Journal of Economics. vol. CV1, N ${ }^{\circ}$ 425, Cambridge, Mass., MIT Press, mayo.

(1992): Macroeconomic policy and long-run growth, $E c 0$ nomic Review, vol. 77, No 4, Kansas City, Mo., Federal Reserve Bank of Kansas City.

Dombusch, R. (1989): Costos y beneficios de la integración económica regional. Una revisión, Pensamiento iberoamericano, $\mathrm{N}^{\circ} 15$, Madrid, Sociedad Estatal Quinto Centenario, enero-junio.

Dutt, A. K. y K. Y. Lee (1993): The service sector and economic growth: some cross-section evidence, International Review of Applied Economics, vol. 3, Londres, Edward Arnold (ed.) mayo.

El-Agra, A. M. (1989): International Trade, New York, St. Martin's Press.

Ellman, M. (1981): Natural gas, restructuring and re-industrialization: The Dutch experience of industrial policy, Terry Baker y Vladimir Brailvasky (eds.) Oil or Industry?, Londres, Academic Press.

Enders, K. y H. Herberg (1983): The Dutch disease: Causes, consequences, cures and calmatives, Weltwirtschaftiches Archiv. Review of World Economics, Band 119, Heft 3, Tübingen, Institut füt Weltwirtschaft Kjel.

Forster, H. y R. H. Ballance (1991): Especialización internacional en el comercio de manufacturas. Una determinación empírica de sus principales determinantes, Pensamiento Iberoame ricano, $N^{\circ} 20$, Madrid, Sociedad Estatal Quinto Centenario.

Fuentes, J. A. (1994): El regionalismo abiento y la integración económica, Revista de la CEPAL, No 53, LC/G.1832-P, Santiago de Chile, CEPAL, agosto.

Funke, N. (1993): Timing and sequencing of reforms: competing views and the role of credibility, Kyklos, vol. 46, facs. 3, Basilea, wwZ and Helbing \& Lichtenhahn Verlag AG.

FUSADES (Fundación Salvadoreña para el Desarrollo Económico y Social), (1991): ¿Qué representa el comercio intra-centro-. americano?. San Salvador, mayo.

Gana, E. (1994): Los cambios estructurales en la integración tatinoamericana y caribeña, Pensamiento iberoamericano, $\mathrm{N}^{\circ}$ 26, Madrid, Socjedad Estatal Quinto Centenario.

Genberg, H. y F, Nadal De Simone (1993): Regional integration agreements and macroeconomic discipline, Kym Anderson y Richard Balckhurt (eds.), Regional Integration and the Global Trading System, Nueva York, St. Martin's Press.

Greenaway, D. y D. Sapsford (1994): What does liberalization do for exports and growth?, Weltwirtschafliches Archiv, Review of World Economics, Band 130, Heft l, Tubingen, Institut für Weltwirtschaft Kiel.

Greenaway, D. y R.C. Hine (1991): Intra-industry specialization, trade expansion and adjustment in the European economic space, Journal of Common Market Studies, vol. $29, \mathrm{~N}^{\circ}$, Oxford, Reino Unido, Basil Blackwe!l Ltd., diciembre.

Greenaway, D., R. Hine y C. Milner (1994): Country-specific factors and the pattern of horizontal and vertical intra-industry trade in the U.K., Weltwirtschaftlichtss Archiv. Review of World Economics, Band 130, Heft 1, Tübingen, Institut für Weltwirtschaft Kiel

Gregory, R. G. (1976): Some implications of the growth of the mineral sector, The Australian Journal of Agricultural Eco. nomics, vol. 20, Sidney, Australian Agricultural Econonics Society, agosto.

Johnson, H. (1976): Panama as a regional financial center: A preliminary analysis of development contribution, Economic De velopment and Cultural Change, vol, $24, \mathrm{~N}^{\circ} 2$, Chicago, Illinois, The University of Chicago, enero,

Jones, I. (1994): Economic growth and the relative price of capital,
Journal of Monetary Economics, vol. 34, № 3, Amsterdam, North-Holland, Publishing Company, Clearance Center, Inc. diciembre.

Kaldor, N. (1981): The energy issues, Terry Baker y Vladimir Brailovsky (eds.) Oil or Industry?, Londres, Academic Press.

Kawai, H. (1994): International comparative analysis of economic growth: Trade liberalization and productivity, The Developing Economics, vol. 32, № 4, Tokio, Institute of Developing Economies, diciembre.

Krugman, P. (1995): Dutch tulips and emerging markets, Foreign Affairs, vol. 74, $\mathrm{N}^{\circ} 4$, Nueva York, Council on Foreign Relations, Inc., julio-agosto.

Lachman R., M. I. Olaso y M. Vallarino (1991): Opciones y dificultades de la integración económica de Panamá con el lstmo Centroamericano, Panamá, Asociación Panameña de Ejecutivos de Empresas, enero.

Lachman R., L. A. Chocano, G. M. Figge y A. O. González (1992): Medios de pago, captación de divisas y problemas financieros en el proceso de la integración economica de Panamá con Centroamérica, Panamá, Asociación Panameña de Ejecutivos de Empresas, septiembre.

Leamer, E., A. Guerra, M. Kaufman y B. Segura (1995): How Does the North American Free Trade Agreement Affect Central America? Policy Research Working Papers, N 1464 , Washington D.C., Banco Mundial, mayo.

Lim, D. (1994): Explaining the growth performance of Asian developing economics, Economic Development and Culural Change, vol. $42, \mathrm{~N}^{\circ} 4$, Chicago, Illinois, University of Chicago.

Loehr, W. (1991): Integration in Central America: Considerations for Panama, Cjudad de Guatemala, Agencia de los Estados Unidos para el Desarrollo Internacional (USAID), mayo.

Magnier, A. y J. Toujas-Bernarte (1994): Technology and trade: Empirical evidence for the major five industrialized countries, Weltwirtschafliches Archiv Review of World Economics, Band 130, Heft , Tübingen, Institut für Weltwirtschaft Kiel,

Markheim, D. (1994): A note on predicting the trade effects of economic integration and other preferential trade agreements: An assessment, Journal of Common Market Studies, vol. 32, $\mathrm{N}^{\circ}$ 1, Oxford, Reino Unido, Basil Blackwell Ltd. marzo.

Murphy, K.M., A. Sheleifer y R.W. Vishny (1989): Industrialization and the Big Push, Journal of Political Economy, vol. 97 , $N^{\circ} 5$, Chicago, University of Chicago Press, octubre.

Panamá (diversos años): Estadística panameña, Contraloría General de la República, Dírección de Estadística y Censo, varios números.

Pelkmans, J. (1982): Customs union and technical efficiency, The Economist, vol. $130, \mathrm{~N}^{\circ} 4$, marzo.

(1991): Towards economic union, Peter Ludlow (ed.), Setting European Community Priorities 1991-1992, Londres, Brassey's.

Peres. Wilson (1993): Efectos dinámicos de la integración económica. Aproximaciones analíticas, Industrialización y desarrotlo tecnológico, LC/G. 1778, Santiago de Chile, CEPAL, septiembre.

Pindyck, R. y A. Solimano (1993): Economic Instability and Aggregate Investment, Policy Research Working Papers, $\mathrm{N}^{\circ} 1148$, Washington, D.C, Banco Mundial.

Primo Braga, C.A., R. Safadi y A. Yeats (1994): Regional integration in the Americas: Déjà Vu all over again, The World Economy, vol. 17, $\mathrm{N}^{\circ} 4$, Oxford, Reino Unido, Blackwell Publishers, julio.

Ranis, G. (1993): Domestic Requirements and Complimentary Folicies for a WHFTA, IDB-ECLAC Working Papers on Trade in The Western Hemisphere $\mathrm{N}^{\circ}$ I6, Washington, D.C., Banco Interamericano de Desartollo (BID), enero.

ROCAP (Regional Office for Central America and Panamá) (1987): Central America Regional Transportation Study, Guatemala, Parsons Brinckerhoff International, mimeo. 
Rodrik, D. (1990): How should structural adjustment programs be designed, World Development, vol.18, $\mathrm{N}^{\circ} 7$, Oxford, Reino Unido, Pergamon Press, julio.

(1991): Policy uncertainty and private investment in developing countries, Joumal of Development Economics, vol. $36, \mathrm{~N}^{\circ}$ 2, Amsterdam, Elsevier, marzo.

(1992): Closing the productivity gap: Does trade liberalization really help?, Trade Policy, Industialization, and Development, Oxford, Reino Unido, Clarendon Press.

(1995): Getting interventions right: How South Korea and Taiwan grew rich, Economic Policy, $\mathrm{N}^{\circ} 20$, Oxford, Rejno Unido, Blackwell Publishers, abril.

Salazar-Xirinachs, J. M. (1990): La nueva integración centroamericana: sus nuevas bases y aspectos relacionados con la incorporación de Panamá, Alajuela, Costa Rica, Instituto Centroamericano de Administración de Empresas (INCAE), noviembre.

SIECA (Secretaría Permanente del Tratado General de Integración Económica Centroamericana) (varios números): Estadisticas macroeconómicas de Centroamérica, Guatemala.

Sleuwaegen. L. y H. Yamawaki (1988): The formation of the European Common Market and changes in market structure and performance, European Economic Review, vol. 32, Amsterdam, Elsevier, septiembre.
Thoumi, F.E. (1994): Panama: Economic integration alternatives, implications, and perspectives, Trade, Industrialization, and Integration in Twentieth-Century Central America, Westport, Conn., Praeger Publishers.

Venables, A. (1994): Integration and the export behavior of firms: Trade costs, trade volumes and welfare, Weltwirtschaftliches Archiv Review of World Economics, Band 130, Heft 1, Tübingen, Institüt für Weltwirtschaft Kiel.

Wolf, M. (1986): Timing and sequence of trade liberalization in developing countries, Asian Development Review. Studies of Asian and Pacific Economic Issues, vol. 4, Manila, Banco Asiático de Desarrollo.

Wonnacott, P. y R. Wonnacott (1981): Is unilateral tariff reduction preferable to a customs unions? The curious case of the missing foreign tariffs, The American Economic Review, vol. $71, N^{\circ} 4$, Los Angeles, California, American Economic Association (AEA), septiembre.

Wood, A. (1994): Give Heckscherer and Ohlin a chance!, Weltwirischafiliches Archiv Review of World Economics, Band 130, Heft 1, Tübingen, Institut für Weltwirtschaft Kjel.

Wood, A. y K. Berge (1994): Exporting Manufactures: Trade Policy or Human Resources?, IDS Working Paper $\mathrm{N}^{\circ} 4$, Sussex, Estados Unidos, Institute of Development Studies, julio. 